\title{
Shifting Perspectives and Collapsing Binaries: Critical Performative Pedagogy in the Performance Studies Classroom
}

\author{
Deborah Newton
}

\begin{abstract}
Much as performance comes into being by the bodily co-presence of performers and audience, so teaching comes into being by the bodily co-presence of teachers and learners, by their encounters and interactions - their relationship. This paper traverses the process dimension of performative teaching and learning by exploring the productive intersections between critical performative pedagogy (CPP) and performance within the performance studies classroom. It does so by examining the power of performativity in the teaching-learning context where, it is claimed, its major characteristic lies in its ability to destabilise and even collapse the inhibitive binary oppositions evident in classrooms purveying a more traditional, conservative culture of the teaching-learning process.
\end{abstract}

\section{Introduction}

This paper aims to discuss and explore performative teaching and learning and how these constructs can actually operate out of the Performance Studies tradition. The importance of this opportunity to elaborate upon this approach is captured well in Warren Mark Liew's paper 'Effects Beyond Effectiveness: Teaching as a Performative Act', in which he states: "Despite its wide disciplinary reach, Performance Studies scholarship remains marginalised in the field of educational studies. A thorough theoretical exposition of performance theories in relation to the study of teaching waits to be written" (2013: 283). I hope I can make just a small contribution towards this aspirational goal of improving teaching and learning by viewing them through performative lenses.

In this paper I want to draw upon my own research into the complex and contested nature of performance, and in particular the concept of the performer-audience relationship, to support my provocation for the urgency of need for a shift in perspective from the myopic, mimetic and parochial 'banking' concept of education, as critically outlined by Paulo Friere (2000), to a more 
contemporary performance understanding as evidenced in Richard Schechner's view, in his broad spectrum approach to performance studies, that education is "one of the four great spheres of performance" (1993: 20-21).

To declare my stance at the outset, from a joint perspective, I share John Warren's sentiment that "My ultimate hope is that as the fields of performance and education become more interdisciplinary, we will pursue linkages between our disciplines promoting a more complex and rich conversation for all" (2007: 1). From my own specific perspective a s a teacher of performance studies, a researcher and active practitioner, I want to promote Monica Prendergast's view "that performance theory has much of value to offer education" (2007: 1). In addition, I advocate a philosophical perspective suggestive of the need to conceptualise the teaching-learning experience as a performative event.

In adopting these theoretical and interdisciplinary views intersecting the boundaries of education, philosophy and performance, aided and abetted by the power of metaphorical analysis, I take a critical theory stance to Cartesian dualism. I do this by taking the terminal cultural binary of teacher-learner and subjecting it to a poststructuralist process of Derridian deconstruction (Derrida 1997), in helping to pave the way to what may be described as a new performative teaching and learning culture.

Finally, I wrap-up this provocative approach to the positive influences of the performative upon the teaching-learning process within the still emerging research trend, which Elyse Lamm Pineau has termed, 'critical performative pedagogy' (CPP) (2002: 42). As an umbrella term, I take CPP firstly, to be an entry point for philosophical discussion concerning the potential of the performative to create the liberating conditions that have the power to remove the shackles of 'enfleshment', a s M cClaren ( 1991: 144-173) u ses the term, so damaging to the aspirational achievements of both learners and teachers. Secondly, to embrace Pineau's conclusion that, "I am convinced that only through means of performance - however broadly one wishes to define it - can liberating pedagogies be developed" (2002: 52), which I see as the fundamental basis to creating this new performative teaching and learning culture.

\section{Shifting Perspectives in Teaching and Learning}

In arguing for a radical shift in perspective of what actually constitutes an effective teaching and learning environment, it is essential to begin by rejecting those traditional understandings which lean heavily on passive, conservative, unitary transmission-reception and mimetic models, which unquestionably privilege the teacher as being empowered and the learner as being disenfranchised.

Felman's assertion that "teaching is... not the transmission of ready-made knowledge but is rather the creation of a new condition of knowledge, the creation of a learning disposition" (Felman 1987: 80); has a similar outcome to that emerging from all encounters between a performer and their audience. As Chris Friend suggests "If we apply the idea of performance-as-creation in a classroom environment, we go against the current trends of standardisation 
and measurement that often distract attention from actual learning and place it instead on drills and test scores" (2012: 2).

In making the point that "Learning outside the classroom is organic, growing out of necessity, and intentional, done with a performative outcome in mind" (ibid.), Friend goes on to ask the stimulating question "How different would education be if performance was the only thing that really mattered?" He sums up his frustration with the current system by saying, "I can't help but wonder how different our education system would be if we focused on learning for learning's sake, rather than for the sake of tests, exams, and homework checks" (ibid.). Perhaps the more balanced approach found in a performative approach to teaching and learning goes some of the way to responding positively to Friend's concerns and aspirations.

It is pivotal to any performative practice environment, and, in my opinion, particularly so to teaching and learning, to adopt a progressive stance involving a shifting emphasis to the importance of understanding the poietic conditions of teaching and learning. To this extent, it seems reasonable to question those views that still continue to proclaim what Colby in 1972 maintained that, "The emphasis has now swung so much towards progressivism that standards are in serious danger" (1972: 1) and progressivists do no more than deliberately or unwittingly promote the party line.

In acknowledging these 'ideological battle-lines' as Colby describes it, attention is now turned to the PS classroom in which it is claimed that its natural performative context results in a critical pedagogy (Shor 1980) which, in focusing emphasis on the relationship between teachers and learners, in the same way that performance stresses the relationship between performer and audience, warmly embraces Pineau's assertion that, "The claim that teaching is a performance is at once self-evident and oxymoronic" (1994: 4). If the construct of teaching and learning is to operate out of the Performance Studies tradition, it is necessary to describe performance studies and CPP as well as explaining their importance of contribution to the creation of a performative teaching and learning environment.

\section{Performance Studies and Critical Performative Pedagogy}

The combination of performance theory (Schechner 2006; Carlson 2004; Fischer-Lichte 2008) and critical pedagogy (Freire 1998, 2000; Shor 1980; Giroux 2011) align with the concept of critical performative pedagogy (CPP) (Pineau 1994). Just as the performer cannot think for the audience nor can the teacher think for the learner. As Warren maintains, "thinking that is concerned about reality, does not take place in ivory tower isolation, but only in communication. If it is true that thought has meaning only when generated by action upon the world, the subordination of students to teachers becomes impossible" (2007: 4).

Using CPP, as a means to progressing towards a performative teaching and learning culture, entails adopting Conquergood's theoretical stance "that aims 
to explore the perspective of 'knowing how' and 'knowing who' rather than a more traditional 'knowing that' and 'knowing about' (Conquergood 2002: 145-156). So, whilst both CPP and performance raise numerous questions about teaching and learning, the critical performative element is found within the 'relationship' between teacher and learner/performer and audience.

This relationship can be described as a form of embodied communicative exchange between teachers and learners equating with that which occurs between performer and audience. This introduces an understanding that applies to both performance and CPP as explained by McLaren in his claim that, "We simply do not exist as bodies, but we also have bodies. We have bodies not just because we are borne into bodies but because we learn our bodies; that is, we are taught how to think about our bodies and how to experience our bodies" (1993: 156). It is this Pontydian concept of embodiment (Merleau-Ponty 1962) and the performance concept of embodied communicative exchange that wedges the performative condition into critical pedagogy, captured in Pineau's term, CPP.

Merleau-Ponty's fame of course lays in his critique of the Cartesian dogmatic concept of dualism, separating mind from body, and replacing it with what he referred to as the 'body-subject', bringing us back to the way things actually appear to us. So, rather than a split between them, the subject and object become one, inferring that the mind and body work in tandem. Trevor Butt puts this so astutely in saying, "the body is not under the control of the mind.... Rather, the body interacts with the world, both finding and constructing meaning within it....When people are the object of study, the subjective and the objective merge into one" (2004: 98). This constructivist approach, as found in the work of Berger and Luckmann (1967), does not see the mind working in isolation, in an either/or sense with the body, but jointly in a 'both/and', or 'as well as' fashion.

So, accepting the thesis that "it is from the body that we think, feel and act" (Butt 2004: 96), evident in Merleau-Ponty's (1962) work, we shift our perspective from the thinking subject of Cartesian dualism, to an action perspective which sees the person, teacher and learner, as a form of motion. Instead of falling prey to 'the natural attitude', as the philosopher Husserl (1970) referred to it, which is the myopic lens through which we see things in a distorted fashion, and is responsible for all the "prejudice we find embedded in cultural tradition" (Butt 2004: 90), we can act as much upon the world as it can act upon us. Learners are not disembodied minds like a piece of 'Cartesian wreckage' (Butt 2004: 130) but free agents engaged in their own personal life projects.

It is this performing body that is at the heart of CPP which maps the interdisciplinary terrain between performance and critical pedagogy. As Pineau puts it, "The turn toward performativity in general, and critical analysis of the performing bodies of teachers and students in particular, has opened an interdisciplinary dialogue that is as politically efficacious as it is theoretically provocative" (2002: 41). In showing how performance shapes pedagogic practice, and explaining exactly what she means by 'the body', Pineau identifies 
three interconnected means of thematising the body: 'the ideological body', 'the ethnographic body' and 'the performing body', the latter of which "yields a repertoire of strategies for curriculum design and classroom instruction that can encourage students' active and critical participation within and beyond the classroom" (ibid.: 42).

As a critical educator, Pineau's CPP decentres teacher authority and is ultimately about empowerment of the learner and I feel she contributes much to the argument for a move toward a performative teaching and learning culture in which students are freed from the oppression of traditional, cultural binary modes of thinking. The importance she attaches to the performative body in the teaching-context recognises that "teaching and learning are fundamentally somatic processes" (2002: 49) and acknowledges the move from theory to practice "is being spearheaded by performance" where enfleshment is more than a theoretical abstraction; it is the disciplinary heart of our pedagogies" (ibid.: 49-50).

McLaren's concept of 'enfleshment' is important for any performative practice and informs much of the thinking behind performative pedagogy. It is clearly important to the new generation of 'liberatory' educators because, as Bell Hooks asserts "those of us trying to critique biases in the classroom have been compelled to return to the body to speak about ourselves as subjects in history... We must return ourselves to a state of embodiment in order to deconstruct the way power has been traditionally orchestrated in the classroom, denying subjectivity to some groups and according it to others" (Hooks 1994: 139).

McLaren's notions of 'enfleshment' and 'refleshment' describe "the dialectical interplay between oppression and resistance" (Pineau 2002: 44) in the classroom. Enfleshment refers to that process which forces bodies to acquire certain habits over our lifetime and which, although appearing to us as if they were natural are, in fact, culturally constructed. Contrary to this understanding, refleshment $r$ efers $t$ o o ur i nnate a bility t o 1 earn a lternative behaviours, corroborating George Kelly's philosophy of 'constructive alternativism' in which he suggests "all our present perceptions are open to question and reconsideration, and it does broadly suggest that even the most occurrences of everyday life might appear utterly transformed if we were inventive enough to construe them differently" (1970a: 1).

Refleshment then confirms th at ou $\mathrm{r}$ ha bits ca $\mathrm{n}$ be broken an d " $w$ hat was learned can be unlearned, and new ways of being can be developed that are more enabling than the old habits" (Pineau 2002: 44). In other words, refleshment desensitises the prejudices we find embedded in our cultural tradition. It is the discipline of performance, as the dance theorist Anne Cooper Albright (1993, cited in Pineau 2002: 45) informs us, "that provides practical methods for breaking through, breaking down, and rebuilding the body's naturalised habits; bodies can be physically retrained and consciously re-theorised" (Albright 1993: 45). CPP, as practised in the PS classroom, embraces refleshment by using performance to intentionally break down those cultural binaries which can be 
extraordinarily powerful in reinforcing and maintaining society's traditional, myopic understanding of teaching and learning. Attention is now turned to just how performance does this.

\section{Collapsing Binaries and Reversing Metaphors}

Cultural binaries, classically manifested in Descartes's mind/body dualism, significantly i mpact a ll a reas of o ur 1 ives. T he i nhibitory p ower of these dichotomous oppositions influences how we think, feel and $b$ ehave. Binaries allow us to deduce various frameworks such as 'this is a teacher' or 'this is a performer'. Take, for example, the binary of presence $v$ absence. Pineau asserts that bodies in the classroom are overwhelmingly inscribed as 'absence' because, steeped in the tradition of Cartesian dualism, "students and teachers effectively have been schooled to 'forget' their bodies when they enter the classroom in order that they might give themselves more fully to the life of the mind" (2002: 45). Described as a form of 'antisomatic prejudice' (Hooks 1994) Pineau concludes that "Schooling systematically domesticates our bodies; it incarcerates them in rows of wooden desks, robs them of spontaneity through rigid demarcations of time and space, and in fact devotes a great deal of energy to hiding the fact that we have bodies at all" (ibid.).

To move toward a performative teaching and learning model, it is essential therefore to highlight how embodiment "disrupts those centrisms that are served by dualistic thinking... and, by consequence, (how) related dualisms.....also become blurred or collapse. When dualistic thinking shifts to multiplex thinking, there is no longer one centre but many, ever shifting centres" (Kisliuk 2002: 107). It is the field of PS that leads the way in this perspective shifting process enabling the conditions that constitute a performative culture.

The research work of Fischer-Lichte (2008) demonstrates how the transformational power of performance transcends rigid oppositions and collapses them replacing their notion of 'either or' with 'as-well-as': "in the place of unbridgeable oppositions we find g radual d ifferences" ( 2008: 2 04). Thus, performance does not separate but connects. As Fischer-Lichte maintains, "The reality of performance cannot be grasped in binary opposition. Performance blurs the boundaries between the social, the political and the ethical which oppositional binaries keep strictly apart" (ibid.: 174).

In her terms performance exposes performers and audiences to autopoietic situations that shatter their safe positions and require them to become co-participants in the performance event. This is clearly evidenced in the performance works of Marina Abramovic, who considers herself, as many others do, to be the 'grandmother of performance art'. Her work transforms the audience into performers; it collapses the opposition between performing and observing. The audience become co-creators in the performance which exemplifies the fact t hat "all p hysical e ncounters b etween p eople stimulate interactions even if their shape is not always plainly evident" (Fischer-Lichte 2008: 43) corroborating Watzlawick et al's (1967) dictum; you cannot not 
react to each other.

By Abramovic inviting her audience into active, creative involvement in her performances, sometimes risking her own life as in Rhythm 0 (1974), where she allows the audience to torture her with a variety of objects including a loaded gun, their traditional role of remaining seated as passive observers could no longer be an option. As Fischer-Lichte states, "Subject and object could no longer be defined and distinguished" ( 2008: 42); subject and object become one, and "the only conditions for these processes to be set in motion lies in the bodily co-presence of actors and spectators, constitutive of performance in general" (ibid.: 43). It is in this sense that the performative focuses on embodiment and embodied communicative exchange, resulting in a redefinition of the performer-audience relationship. The fundamental bodily co-presence of performer and audience creates (metacommunicative) interactions which occur, albeit at a 'barely perceptible level' (ibid.), which result in the collapsing of the performer-audience binary and establish a relationship which privileges the audience as much as it does the performer.

For Fischer-Lichte performance is not so much an art but an experiential event which involves everyone present. Seen as an event, she illuminates an understanding of performance as being transformational. In analysing Abramovic's work, for example, she states, "Instead of a work of art that existed independently of her and her recipient.... .rather they were all involved in a common situation of here and now, transforming everyone present into co-subjects... . the relationship between subject and object was established not as dichotomous but as oscillatory" (ibid.: 17). Thus, performance must be seen as a radical approach to the mind-body dichotomy not only destabilising it but "erasing it uncompromisingly" (ibid.: 173). In this sense embodiment is a creative process in which the mind clearly does not exist in opposition to the body and is "an entirely inappropriate concept to describe human experience" (ibid.).

Applying Fischer-Lichte's thesis to teaching, seeing it not as an art but as a performative 'event' involving learners in a transformational experience where cultural binaries such as, mind-body, subject-object, speaker-listener, expert-novice, passive-active and, of course, teacher-learner, are collapsed and fused together, opening up classrooms as performative spaces where, as Perry and Medina maintain, "embodiment isn't simply an interesting possibility for education, nor is it an alternative practice or method: embodiment is" (2011: 63). This is why CPP considers the body itself as a place of learning and experience (Pineau, 2002: 44), or as Ellsworth puts it, "a learning self that is in motion" (Ellsworth 2005: 7). Here we see a conjoin between performance and teaching. Both possess a transformative potential in motivating participants that "opens up the possibility for all participants to experience a metamorphosis" (Fischer-Lichte 2008: 23) incorporating the reversal of roles; a redefinition of the teacher-learner relationship challenging the perceived binary oppositions which have perpetuated and legitimised the dominance of the teaching role over the learner, to which attention is now turned. 


\section{Reversing Metaphors}

In respect of its implications for 'liberatory education', in 1985, Newton and Mathews published a prophetic article in which they contended that the process of learning could be democratised and enhanced by taking a metaphorical perspective to its analysis and consequent understanding. This contention stemmed from their research in HE classrooms that, more often than not, 'control of learning', lay not in the hands of learners but teachers. Adopting a Wittgensteinian (1997) position that 'all seeing is seeing as', the authors claimed that the best way to enhance learning was to hand control back to learners by seeing the "learner 'as' teacher" and "teacher 'as' learner"... "to share in the process of teaching and learning ... to become partners in education" (Newton and Mathews 1985: 29). This metaphorical process culminated in the conclusion that seeing both learner and teacher 'as' researchers, engaging "in essentially the same type of activity" (Newton and Mathews 1985: 30), is the required perceptual framework for any initiatives making claim to enhancing learning.

Acknowledging the potential metaphorical value of Newton and Matthews' (1985) research findings, it is fairly easy to see how their work can be correlated with that of Fischer-Lichte, by viewing performers and audiences, and teachers and learners, as all being researchers, construing or hypothesising (Kelly 1970) their way through life in a social autopoietic context of performative relationships. CPP, in this respect, as a performative model of teaching, enables the creation of the autopoietic conditions which presents 'teaching as performative' in which "the autopoietic feedback loop, consisting of the mutual interaction between actors (teachers) and spectators (learners), brings forth the performance" (Fischer-Lichte 2008: 163). In rejecting the dominant-submissive binary evident in classrooms, and acknowledging the interdependence of teachers and learners through the deconstruction of the 'teacher as learner', by reversing the metaphor and shifting the privileged term to learner, we begin to appreciate the implications and applications of a CPP for understanding the 'liminality' of the teaching-learning process as it is understood in the performance context.

\section{Conclusion}

In this paper I have contended that CPP has the transformational power to shift our perceptions of teaching and learning to a view that positions the embodied teacher and learner in the PS classroom such that it may become the centre of research efforts to enhance both educational processes. Furthermore, the central focus of such research effort should direct its attention at the relationship between teacher and learner in a concerted attempt to break down pervasive cultural binaries thus permitting us to see learners and teachers alike as sharing a liminal educational experience. This leads to the conclusion, that only a reconceptualisation of the teacher-learner relationship as discussed along these 
embodied, performative lines can effect a critical and necessary change in how we educate our future performance practitioners.

Put concisely, the principles of CPP should be transferred to the PS classroom to establish a performative teaching and learning culture in which knowledge acquisition becomes a mutual process between teachers and learners rather than an object produced by teachers for students. This approach argues for performance scholars to engage a critical performative pedagogy with performative praxis and challenges teachers of performance to design and deliver their courses in ways that obviate and focus upon the benefits of establishing an effective teacher-learner relationship which serves to enhance the collaborative, performative nature of teaching.

In conclusion, the liminal or threshold aspect of teaching and learning, that boundary 'betwixt and between' (Turner 1969) them, which CPP encourages participants to cross over, is highly evident in the PS classroom, where identity formation, relationship development and knowledge acquisition go hand in hand with performance theory, suggesting that every one of us puts on a performance in society (Goffman 1969). Teachers and learners are of course no exception in this respect. However, only by intentionally shifting our perspectives of teaching and learning incorporating an embodied redefinition of the relationship between teachers and learners together with a metacommunicative reversal of roles, in which learners are seen as responsible, empowered co-determinants of educational outcomes, and by disassembling those cultural binaries which induce a perceptual artificiality of the classroom, will we establish the performative teaching and learning culture to which CPP makes such an important contribution.

\section{Bibliography}

Albright, Alison C. (1993): Dancing across Difference: Experience and Identity in the Classroom. In: Women and Performance 6, 41-54

Berger, Peter; Luckmann, Thomas (1967): The Social Construction of Reality. Harmondsworth: Penguin

Butt, Trevor (2004): Understanding People. Palgrave: MacMillan

Carlson, Marvin (2004): Performance: A Critical Introduction. London: Routledge

Colby, Roy (1972): 'Progressive People: Those who deliberately or unwittingly promote the Party Line'. A Communese-English Dictionary. Western Islands Publishers: Massachusetts. Online Resource: THE TRADITIONAL AND PROGRESSIVE PHILOSOPHIES OF EDUCATION. Online Resource: http://www.cre.org.uk/philosophies.html (Accessed 16 April 2014)

Conquergood, Dwight (2002): Performance studies: Interventions and radical research. TDR: The Drama Review 46, 145-156 
Derrida, Jacques (1997): Of Grammatology. Baltimore \& London: Johns Hopkins University Press 1997, corrected edition, trans. Gayatri Chakravorty Spivak

Descartes, René (1641): Meditations on First Philosophy. In: The Philosophical Writings of René Descartes, trans. by J. Cottingham, R. Stoothoff and D. Murdoch. Cambridge: Cambridge University Press 1984, vol. 2, 1-62

Ellsworth, Elizabeth (2005): Places of learning: Media, architecture, pedagogy. New York: Routledge

Felman, Shoshana (1987): Jacques Lacan and the adventure of insight. Psychoanalysis in contemporary culture. Boston: Harvard University Press

Fischer-Lichte, Erika (2008): The Transformative Power of Performance: A new aesthetics. Trans. Saskya Iris Jain. London: Routledge

Freire, Paulo (1998): Pedagogy of Freedom: Ethics, Democracy, and Civic Courage (Clarke, P., Trans.). Maryland: Rowman \& Littlefield

Freire, Paulo (2000): Pedagogy of the Oppressed. New York: Continuum

Friend, Chris (2012): Learning as Performance: MOOC Pedagogy and On-ground Classes. Online Resource: http://www.hybridpedagogy.com/journal/learning-as-peformance-moocpedagogy-and-on-ground-classes/\#respond (Accessed 24 August 2014)

Giroux, Henry A. (2011): On Critical Pedagogy. London: The Continuum International Publishing Group

Goffman, Erving (1969): The presentation of the self in everyday life. London. Allen Lane

Hooks, Bell (1994): Teaching to Transgress: Education as the Practice of Freedom. New York: Routledge

Husserl, Edmund (1970): The Crisis of European Sciences and Transcendental Phenomenology. An Introduction to Phenomenological Philosophy. Evanston, Illinois: Northwestern University Press

Kelly, George (1970): A brief introduction to personal construct theory. In: D. Bannister (Ed.): Perspectives in Personal Construct Theory. London: Academic Press. Reprinted 1985, London: Centre for Personal Construct Theory

Kisliuk, Michelle (2002): The Poetics and Politics of Practice: Experience, Embodiment, and the Engagement of Scholarship. In: Nathan Stucky and Cynthia Wimmer (eds.): Teaching Performance Studies, 99-117. Carbondale, Illinois: Southern Illinois University Press

Liew, Warren Mark. (2013): Effects Beyond Effectiveness. Teaching as a Performative Act. Curriculum Inquiry 43, 2, 261-288

McLaren, Peter (1991): Schooling the Postmodern Body: Critical Pedagogy and the Politics of Enfleshment. In: Giroux, Henry (ed.): Postmodernism, Feminism, and cultural Politics: Redrawing Educational Boundaries. New York: State University of New York 
McLaren, Peter (1993): Schooling as a Ritual Performance: Toward a Political Economy of Educational Systems and Gestures (2 ${ }^{\text {nd }}$ Ed.). New York: Routledge

Merleau- Ponty, Maurice (1962): Phenomenology of Perception. London: Routledge

Newton, Robert J.; Mathews, Peter V. (1985): The Study Skills Paradox: "You Can Bring a Horse to Water But You Cannot Make it Drink". In: The Vocational Aspect of Education Vol 37, No 96, 23-31

Perry, Mia; Medina, Carmen (2011): Embodiment and Performance in Research: Investigating the Possibility of the Body in Curriculum Experience. In: Journal of Curriculum Theorising Vol 27, No 3, 62-75

Pineau, Elyse L. (1994): Teaching is Performance: Reconceptualizing a Problematic Metaphor. In: American Educational Research Journal 31, 3-25

Pineau, Elyse L. (2002) Critical Performative Pedagogy: Fleshing Out the Politics of Liberatory Education. In: Stucky, Nathan; Wimmer, Cynthia (eds.): Teaching Performance Studies. Carbondale, Illinois: Southern Illinois University Press, 41-54

Prendergast, Monica (2007) Bryant, K. Alexander; Anderson, G. L.; Gallegos. P. (2005) (eds.): Performance Theories in Education: Power, Pedagogy and the Politics of Identity. Mahwah, NJ: Lawrence Erlbaum. Theatre Research in Canada Vol. 28 No. 2. Online Resource: http:

//journals.hil.unb.ca/index.php/tric/article/view/11128/11832 (Accessed 8 April 2014)

Schechner, Richard (1993): The future of Ritual. London: Routledge

Schechner, Richard (2006): Performance Studies: An Introduction. London: Routledge

Shor, Ira (1980): Critical Teaching and Everyday Life. Boston, Massachusetts: South End Press

Turner, Victor (1969): The Ritual Process: Structure and Anti-Structure. Chicago: Aldine Publishing Company

Warren, John (2007): Editors Introduction: Pedagogy and Performance. Liminalities Vol 3, Issue 1 (n. pag.)

Watzlawick, Paul; Bavelas, Janet B.; Jackson, Donald D. (1967): Pragmatics of Human Communication: A Study of interactional Patterns, Pathologies and Paradoxes. New York: W. W. Norton and Company Inc.

Wittgenstein, Ludwig (1972): Philosophical Investigations. Oxford: Blackwell 